\title{
Plasma bicarbonate and risk of type 2 diabetes mellitus
}

\author{
Ernest I. Mandel MD SM, Gary C. Curhan MD ScD, Frank B. Hu MD PhD, Eric N. Taylor MD MSc
}

\begin{abstract}
Background: Several biomarkers of metabolic acidosis, including lower plasma bicarbonate and higher anion gap, have been associated with greater insulin resistance in cross-sectional studies. We sought to examine whether lower plasma bicarbonate is associated with the development of type 2 diabetes mellitus in a prospective study.
\end{abstract}

Methods: We conducted a prospective, nested case-control study within the Nurses' Health Study. Plasma bicarbonate was measured in 630 women who did not have type 2 diabetes mellitus at the time of blood draw in 19891990 but developed type 2 diabetes mellitus during 10 years of follow-up. Controls were matched according to age, ethnic background, fasting status and date of blood draw. We used logistic regression to calculate odds ratios (ORs) for diabetes by category of baseline plasma bicarbonate.
Results: After adjustment for matching factors, body mass index, plasma creatinine level and history of hypertension, women with plasma bicarbonate above the median level had lower odds of diabetes (OR $0.76,95 \%$ confidence interval [Cl] 0.60-0.96) compared with women below the median level. Those in the second (OR 0.92, 95\% Cl 0.67-1.25), third (OR 0.70, $95 \% \mathrm{Cl} 0.51-0.97)$ and fourth (OR $0.75,95 \% \mathrm{Cl}$ 0.54-1.05) quartiles of plasma bicarbonate had lower odds of diabetes compared with those in the lowest quartile ( $p$ for trend $=0.04$ ). Further adjustment for C-reactive protein did not alter these findings.

Interpretation: Higher plasma bicarbonate levels were associated with lower odds of incident type 2 diabetes mellitus among women in the Nurses' Health Study. Further studies are needed to confirm this finding in different populations and to elucidate the mechanism for this relation.
Competing interests: Ernest Mandel has received research support from the American Kidney Fund Clinical Scientist in Nephrology Program. Gary Curhan is financially involved in UpToDate, Inc. (author, section editor) and the American Society of Nephrology (Clinical Journal of the American Society of Nephrology, editor-in-chief). No competing interests declared by Frank Hu or Eric Taylor.

This article has been peer reviewed.

Correspondence to: Ernest I. Mandel, emandel@partners.org

CMAJ 2012. DOI:10.1503 /cmaj.120438
$\mathrm{R}$ esistance to insulin is central to the pathogenesis of type 2 diabetes mellitus. ${ }^{1}$ Several mechanisms may lead to insulin resistance and thereby contribute to the development of type 2 diabetes mellitus, including altered fatty acid metabolism, mitochondrial dysfunction and systemic inflammation. ${ }^{2}$ Metabolic acidosis may also contribute to insulin resistance. Human studies using the euglycemic and hyperglycemic clamp techniques have shown that mild metabolic acidosis induced by the administration of ammonium chloride results in reduced tissue insulin sensitivity. ${ }^{3}$ Subsequent studies in rat models have suggested that metabolic acidosis decreases the binding of insulin to its receptors. ${ }^{4,5}$ Finally, metabolic acidosis may also increase cortisol production, ${ }^{6}$ which in turn is implicated in the development of insulin resistance.?

Recent epidemiologic studies have shown an association between clinical markers of metabolic acidosis and greater insulin resistance or prevalence of type 2 diabetes mellitus. In the National Health and Nutrition Examination Sur- vey, both lower serum bicarbonate and higher anion gap (even within ranges considered normal) were associated with increased insulin resistance among adults without diabetes. ${ }^{8}$ In addition, higher levels of serum lactate, a small component of the anion gap, were associated with higher odds of prevalent type 2 diabetes mellitus in the Atherosclerosis Risk in Communities study ${ }^{9}$ and with higher odds of incident type 2 diabetes mellitus in a retrospective cohort study of the risk factors for diabetes in Swedish men. ${ }^{10}$ Other biomarkers associated with metabolic acidosis, including higher levels of serum ketones,${ }^{11}$ lower urinary citrate excretion ${ }^{12}$ and low urine $\mathrm{pH},{ }^{13}$ have been associated in crosssectional studies with either insulin resistance or the prevalence of type 2 diabetes mellitus. However, it is unclear whether these associations are a cause or consequence. We sought to address this question by prospectively examining the association between plasma bicarbonate and subsequent development of type 2 diabetes mellitus in a nested case-control study within the Nurses' Health Study. 


\section{Methods}

\section{Study population}

The Nurses' Health Study in the United States began in 1976, enrolling 121700 female registered nurses aged 30-55 years who returned an initial questionnaire that provided detailed health-related information. Participants were followed by use of biennial mailed questionnaires. The follow-up for the cohort exceeds $90 \%$ of eligible person-time.

During 1989-1990, a total of 32826 women who were free of diagnosed diabetes, coronary heart disease, stroke or cancer provided blood samples. From this group, we identified 691 women in whom type 2 diabetes mellitus was diagnosed between 1990 and 2000 (cases). Controls were matched 1:1 to cases by age, ethnic background, date of blood draw and fasting status at blood draw. An additional control was matched based on these characteristics as well as body mass index (BMI) to each of the most obese women (cases in the top 10\% of the BMI distribution in the Nurses' Health Study) to improve statistical control for obesity; this yielded 2 controls for each of the most obese cases. Thus, we began our study with 691 cases and 799 controls. After excluding women whose samples were unable to be assayed (26 cases and 35 controls), those with processing delays (34 cases and 33 controls), one control missing data for plasma bicarbonate and one case with an outlier value, we analyzed data for 630 cases and 730 controls.

This study was approved by the institutional review board of Partners HealthCare System, Boston, MA.

\section{Ascertainment of diabetes}

Cases of type 2 diabetes mellitus were identified by self-report on the biennial questionnaire and confirmed by the use of a supplementary questionnaire that queried symptoms, diagnostic laboratory test results and diabetes treatment. ${ }^{14}$ The diagnosis ascertained from the supplementary questionnaire was validated in a subset of individuals in this cohort using medical record review, with agreement exceeding $98 \% .{ }^{14}$ For the present study, diabetes must have been diagnosed at least 1 year after the date of blood collection to be classified as incident.

\section{Assessment of covariates}

Exposures, including body weight, physical activity, smoking status, menopausal status, use of postmenopausal hormones, and newly diagnosed medical conditions, were updated every 2 years by questionnaire. Physical activity reported on questionnaires was converted into metabolic equivalents (METs) using an established coding system. ${ }^{15}$ Diet and alcohol consumption were assessed in 1980, 1984, 1986 and 1990 by use of semiquantitative questionnaires about food frequency. Diet exposures and physical activity were calculated as updated cumulative average levels as of the baseline (1990) questionnaire. We also summarized intake of cereal fibre and trans fats, glycemic load and the ratio of polyunsaturated to saturated fats (with each component categorized in quintiles and scored $1-5$, where 5 was assigned to the healthiest intake) in a diabetes diet score (ranging from 4-20), with a high diet score associated with a reduced risk of type 2 diabetes mellitus in the Nurses' Health Study. ${ }^{16}$ The reproducibility and validity of the food-frequency questionnaires have been described. ${ }^{17,18}$ Reported weights have been shown to correlate with measured weights $(r=0.97) .{ }^{19}$ The assessment of physical activity has also been validated. ${ }^{20}$

\section{Laboratory procedures}

In 1989-1990, women who agreed to provide a blood sample were sent a phlebotomy kit. The samples, kept cool by use of frozen water bottles, were returned by overnight mail. On arrival, the samples were processed and frozen in liquid nitrogen $\left(-130^{\circ} \mathrm{C}\right)$ until analysis; $97 \%$ arrived within 26 hours of phlebotomy. All assays were performed on aliquots from these stored samples.

Plasma bicarbonate was measured using an enzymatic technique on a Hitachi 917 analyzer using reagents and calibrators from Roche Diagnostics. Study samples were analyzed in randomly ordered case-control pairs or triplets (for those with an additional control matched on BMI) to reduce systematic bias and inter-assay variation. The intra-assay coefficient of variation was $4.5 \%$. However, our previous pilot studies of plasma bicarbonate suggested greater variability with longer processing times (within-person correlation was 0.72 for samples processed at $0 \mathrm{~h}$ compared with at $24 \mathrm{~h}$; 0.15 for samples processed at $0 \mathrm{~h}$ compared with at $48 \mathrm{~h}$ ). Therefore, we excluded participants with processing times greater than 24 hours (34 cases and 33 controls). Creatinine was measured using a modified Jaffe method and glomerular filtration rate was estimated by use of the CKD-EPI (Chronic Kidney Disease Epidemiology Collaboration) equation. ${ }^{21} \mathrm{C}$-reactive protein levels were measured via a high-sensitivity latex-enhanced immunonephelometric assay (Dade Behring). Insulin levels were measured by use of a double antibody system with less than $0.2 \%$ cross-reactivity between insulin and its precursors (Linco Research). 
Hemoglobin $\mathrm{A}_{1 \mathrm{c}}$ was measured by immunoassay (Roche Diagnostics). The coefficients of variation were $<6.5 \%$ for creatinine, $<4.5 \%$ for C-reactive protein, $<12 \%$ for insulin and $<3.0 \%$ for hemoglobin $\mathrm{A}_{1 \mathrm{c}}$.

\section{Statistical analysis}

In our nested case-control study, the controls represent the distribution of characteristics in the source population. Therefore, we divided the distribution of plasma bicarbonate at the median and

Table 1: Baseline characteristics of the study population by case status

\begin{tabular}{|c|c|c|c|}
\hline \multirow[b]{2}{*}{ Characteristic } & \multicolumn{2}{|c|}{ Median (IQR)* } & \multirow[b]{2}{*}{$p$ valuet } \\
\hline & $\begin{array}{c}\text { Cases } \\
n=630\end{array}$ & $\begin{array}{l}\text { Controls } \\
n=730\end{array}$ & \\
\hline Age at blood draw, yr, mean \pm SD & $56.1 \pm 6.5$ & $56.1 \pm 6.6$ & matching \\
\hline White, \% & 98 & 98 & matching \\
\hline Body mass index, $\mathrm{kg} / \mathrm{m}^{2}$ & $29.9(26.3-33.7)$ & $25.6(22.9-30.9)$ & $<0.01$ \\
\hline \multicolumn{2}{|l|}{ Smoking status, \% } & & 0.2 \\
\hline Never smoked & 46 & 48 & \\
\hline Past smoker & 42 & 42 & \\
\hline Current smoker & 12 & 10 & \\
\hline Activity, METs/wk‡ & $8.6(3.8-18.7)$ & $12.2(5.2-23.0)$ & $<0.01$ \\
\hline Alcohol intake, g/d & $1.0(0-3.7)$ & $2.5(0.4-8.0)$ & $<0.01$ \\
\hline Animal protein intake, $\mathrm{g} / \mathrm{d}$ & $57.8(50.9-64.8)$ & $56.4(49.2-63.1)$ & $<0.01$ \\
\hline Potassium intake, mg/d & $2863(2577-3171)$ & $2868(2570-3205)$ & 0.6 \\
\hline Total calcium intake, mg/d & $859(676-1062)$ & $865(685-1109)$ & 0.3 \\
\hline Magnesium intake, mg/d & $286(252-322)$ & $290(257-332)$ & 0.08 \\
\hline Cereal fibre intake, $\mathrm{g} / \mathrm{d}$ & $3.6(2.8-4.6)$ & $3.7(2.9-4.8)$ & 0.04 \\
\hline Trans fat intake, g/d & $3.2(2.8-3.8)$ & $3.2(2.7-3.8)$ & 0.2 \\
\hline Glycemic index & $52.7(50.8-54.5)$ & $52.2(50.3-54.3)$ & 0.02 \\
\hline Diabetes diet score§ & $11.0(9.0-14.0)$ & $12.0(10.0-14.0)$ & 0.01 \\
\hline COPD, \% & 14 & 12 & 0.2 \\
\hline Hypertension, \% & 52 & 31 & $<0.01$ \\
\hline Hypercholesterolemia, \% & 49 & 39 & $<0.01$ \\
\hline Thiazide use, \% & 24 & 16 & $<0.01$ \\
\hline Family history of diabetes, $\%$ & 48 & 23 & $<0.01$ \\
\hline $\begin{array}{l}\text { Use of postmenopausal } \\
\text { hormones, } \%\end{array}$ & & & 0.09 \\
\hline Premenopausal & 21 & 23 & \\
\hline Past use & 12 & 11 & \\
\hline Current use & 30 & 35 & \\
\hline Never used & 37 & 31 & \\
\hline Fasting at blood draw, \% & 67 & 65 & matching \\
\hline Creatinine, mg/dL & $0.67(0.60-0.76)$ & $0.69(0.62-0.77)$ & $<0.01$ \\
\hline Estimated GFR, $\mathrm{mL} / \mathrm{min} / 1.73 \mathrm{~m}^{2}$ & $97.4(88.3-104.6)$ & $96.4(86.2-102.6)$ & 0.02 \\
\hline C-reactive protein, $\mathrm{mg} / \mathrm{dL}$ & $0.37(0.20-0.62)$ & $0.15(0.07-0.34)$ & $<0.01$ \\
\hline Hemoglobin $\mathrm{A}_{1 c^{\prime}} \%$ & $6.1(5.8-6.5)$ & $5.6(5.4-5.8)$ & $<0.01$ \\
\hline Insulin, $\mu \mathrm{U} / \mathrm{mL}$ & $11.3(7.1-16.9)$ & $9.0(5.0-12.7)$ & $<0.01$ \\
\hline Plasma bicarbonate, $\mathrm{mmol} / \mathrm{L}$ & $22.0(20.2-23.7)$ & $22.4(20.5-23.9)$ & 0.02 \\
\hline $\begin{array}{l}\text { Note: } \text { COPD }=\text { chronic obstructive pulmon } \\
\text { METs }=\text { metabolic equivalents, SD }=\text { standa } \\
\text { *Unless otherwise stated. } \\
t p \text { values are from the Student } t \text { test for } \mathrm{cl} \\
\text { medians, and } \chi^{2} \text { test for those reported as } \\
\text { ‡Physical activity reported on questionnair } \\
\text { §Diabetes scores ranged from } 4 \text { to } 20 \text {, with }\end{array}$ & $\begin{array}{l}\text { disease, GFR = glomerul } \\
\text { deviation. } \\
\text { acteristics reported as } m \\
\text { rcentages. } \\
\text { was converted into MET } \\
\text { gher scores associated } v\end{array}$ & $\begin{array}{l}\text { tration rate, IQR = inter } \\
\text { Wilcoxon rank sum tes } \\
\text { an established coding } \\
\text { reduced risk of type } 2\end{array}$ & $\begin{array}{l}\text { rge, } \\
\text { reported as } \\
\text { ellitus. }\end{array}$ \\
\hline
\end{tabular}


into quartiles according to the distribution in the control group. Further, to gain insight into factors associated with plasma bicarbonate that could potentially confound its association with diabetes, we examined baseline characteristics of controls by quartile of plasma bicarbonate. We compared baseline participant characteristics using $t$ tests, analysis of variance, Wilcoxon rank-sum tests, Kruskal-Wallis tests or $\chi^{2}$ tests. Application of our exclusion criteria led to 11 unmatched cases and 33 unmatched controls. To maximize the size of our study population, we used unconditional logistic regression to estimate the odds ratios (ORs) and 95\% confidence intervals (CIs) for the levels of plasma bicarbonate and the development of type 2 diabetes mellitus. We adjusted all models for matching factors, and we used a priori knowledge to include BMI, plasma creatinine and history of hypertension as obligatory covariates in our model. We considered potential confounders, both those possibly associated with our exposure of interest and those associated with type 2 diabetes mellitus. These included a history of hypercholesterolemia or chronic obstructive pulmonary disease, thiazide use, family history of diabetes, smoking, alcohol intake, physical activity, menopausal status, postmenopausal hormone use, diabetes diet score, and the intake of animal protein, potassium, calcium and magnesium. We constructed a parsimonious model that included only the covariates determined to be confounders, which we defined as those that changed the point estimate by more than $10 \%$. Finally, we added C-reactive protein to the final model to assess whether this marker of inflammation attenuated the relation between plasma bicarbonate and diabetes.

\section{Results}

At baseline, women in whom type 2 diabetes mellitus later developed had a higher BMI and a greater prevalence of hypertension, hypercholesterolemia and family history of diabetes than those without diabetes (Table 1). Further, they were less physically active, had lower alcohol consumption, lower intake of cereal fibre, greater intake of trans fats and had a higher glycemic index. The mean plasma bicarbonate level was significantly lower among those in whom diabetes subsequently developed $(p=0.02)$. Among those with available levels, the baseline levels of C-reactive protein (619 cases and 471 controls), fasting insulin (393 cases and 354 controls) and hemoglobin $\mathrm{A}_{1 \mathrm{c}}$ (341 cases and 416 controls) were all higher among those with subsequently diagnosed diabetes.

Baseline characteristics of controls, by quartile of plasma bicarbonate, are shown in Table 2 .
Those in the highest quartile tended to be older, have a lower BMI, higher levels of physical activity, a greater prevalence of hypertension and thiazide use, and slightly higher intakes of potassium and calcium.

Each unit increase in plasma bicarbonate was associated with a $4 \%$ decrease in the odds of diabetes after adjustment for matching factors (OR $0.96,95 \%$ CI $0.92-1.00 ; p=0.03$ ) and after further adjustment for BMI, plasma creatinine and history of hypertension (OR $0.96,95 \%$ CI 0.92 $1.00 ; p=0.05)$.

Women with plasma bicarbonate above the median level among controls in our cohort (22.4 $\mathrm{mmol} / \mathrm{L}$ ) had lower odds of incident diabetes (OR 0.77, 95\% CI 0.62-0.96; $p=0.02$ ) compared with those below the median after adjustment for matching factors. The ORs were essentially unchanged after further adjustment for BMI, plasma creatinine and history of hypertension (OR 0.76, 95\% CI 0.60-0.96; $p=0.02)$. We further divided plasma bicarbonate into quartiles. Higher plasma bicarbonate was associated with lower odds of incident diabetes across the quartiles in both the crude ( $p$ for linear trend $=0.03$ ) and adjusted models ( $p$ for linear trend $=0.04$ ) (Table 3). Additional adjustment for history of hypercholesterolemia, history of chronic obstructive pulmonary disease, thiazide use, smoking, physical activity, family history of diabetes, menopausal status, use of postmenopausal hormones, alcohol intake and diabetes diet score did not appreciably alter the estimates for the median or quartile analyses, nor did adjustment for intake of animal protein, potassium, calcium and magnesium. Conditional logistic regression in the subgroup with matched cases and controls yielded similar results.

Given the association of obesity with type 2 diabetes mellitus, we considered BMI in 3 ways (continuously, continuously with both a linear and squared term, and in categories $[<25.0$, $25.0-29.9, \geq 30.0]$ ) in 3 different models to ensure adequate control for confounding by BMI. The point estimates did not change regardless of the method of controlling for BMI. Finally, to minimize confounding by obesity, we added waist circumference to linear BMI in a secondary analysis, and we observed similar results.

Because incipient type 2 diabetes mellitus can precede overt diagnosis by several years, we performed an additional analysis excluding women ( $n=181$ cases) who received a diagnosis of diabetes in the first 4 years of follow-up, and we observed similar results.

Recent practice guidelines have been revised to include hemoglobin $\mathrm{A}_{\mathrm{lc}}$ greater than $6.5 \%$ as a diagnostic criterion for diabetes. ${ }^{22}$ In our study, 98 
cases and 6 matched controls had hemoglobin $\mathrm{A}_{\mathrm{lc}}$ levels greater than $6.5 \%$ at the baseline blood draw. We performed an additional analysis excluding these individuals, and we observed similar results.
Systemic inflammation, marked by elevated C-reactive protein, is associated with both low serum bicarbonate ${ }^{23}$ and the development of type 2 diabetes mellitus, ${ }^{24}$ and it may underlie

Table 2: Baseline characteristics of controls by quartile of plasma bicarbonate

\begin{tabular}{|c|c|c|c|c|c|}
\hline \multirow[b]{2}{*}{ Characteristic } & \multicolumn{4}{|c|}{ Quartile of plasma bicarbonate; median (IQR)* } & \multirow[b]{2}{*}{$p$ value $\neq$} \\
\hline & $\begin{array}{c}\text { Quartile 1 } \\
\text { (<20.6 mmol/L) } \\
n=189\end{array}$ & $\begin{array}{c}\text { Quartile 2 } \\
\text { (20.6-22.3 mmol/L) } \\
n=176\end{array}$ & $\begin{array}{c}\text { Quartile } 3 \\
\text { (22.4-23.9 mmol/L) } \\
n=183\end{array}$ & $\begin{array}{c}\text { Quartile } 4 \\
\text { (> } 23.9 \mathrm{mmol} / \mathrm{L}) \\
n=182\end{array}$ & \\
\hline $\begin{array}{l}\text { Age at blood draw, yr, mean } \\
\pm \text { SD }\end{array}$ & $54.0 \pm 5.0$ & $55.8 \pm 5.1$ & $56.4 \pm 5.1$ & $56.6 \pm 4.9$ & $<0.01$ \\
\hline White, \% & 99 & 97 & 99 & 99 & 0.9 \\
\hline Body mass index, $\mathrm{kg} / \mathrm{m}^{2}$ & $26.6(22.7-30.9)$ & $25.6(22.5-31.9)$ & $25.8(23.5-30.7)$ & $24.9(22.9-29.3)$ & 0.2 \\
\hline Smoking status, \% & & & & & 0.01 \\
\hline Never smoked & 48 & 49 & 45 & 56 & \\
\hline Past smoker & 33 & 42 & 48 & 34 & \\
\hline Current smoker & 19 & 9 & 7 & 10 & \\
\hline Activity, METs/wk§ & $11.4(4.6-23.3)$ & $11.8(5.9-21.4)$ & $10.9(4.2-22.0)$ & $15.0(6.3-26.3)$ & 0.04 \\
\hline Alcohol intake, g/d & $2.2(0.5-7.8)$ & $2.8(0.5-7.6)$ & $1.7(0.2-7.5)$ & $3.2(0.4-9.4)$ & 0.3 \\
\hline Animal protein intake, $\mathrm{g} / \mathrm{d}$ & $56.5(49.0-62.2)$ & $55.6(49.5-62.8)$ & $55.8(48.4-63.4)$ & $57.7(49.6-64.1)$ & 0.7 \\
\hline Potassium intake, mg/d & 2857 (2519-3187) & $2842(2549-3164)$ & $2866(2584-3250)$ & 2907 (2610-3222) & 0.6 \\
\hline Total calcium intake, mg/d & $856(679-1098)$ & $843(679-1080)$ & $877(638-1136)$ & $890(745-1121)$ & 0.3 \\
\hline Magnesium intake, mg/d & $287(257-320)$ & $290(257-333)$ & $288(256-334)$ & $295(258-329)$ & 0.9 \\
\hline Cereal fibre intake, g/d & $3.7(2.9-5.0)$ & $3.9(2.9-4.7)$ & $3.8(2.9-4.8)$ & $3.5(2.9-4.8)$ & 0.9 \\
\hline Trans fat intake, g/d & $3.3(2.8-3.8)$ & $3.2(2.7-3.8)$ & $3.2(2.7-3.9)$ & $3.3(2.7-3.8)$ & 0.8 \\
\hline Glycemic index & $52.3(50.4-54.7)$ & $52.2(50.4-54.2)$ & $52.3(50.2-54.5)$ & $51.9(49.9-53.8)$ & 0.4 \\
\hline Diabetes diet scoreף & $12.0(10.0-14.0)$ & $12.0(10.0-14.0)$ & $12.0(10.0-14.0)$ & $12.0(10.0-14.0)$ & 0.9 \\
\hline COPD, $\%$ & 14 & 15 & 11 & 8 & 0.2 \\
\hline Hypertension, \% & 22 & 28 & 34 & 36 & 0.04 \\
\hline Hypercholesterolemia, \% & 39 & 35 & 42 & 34 & 0.4 \\
\hline Thiazide use, $\%$ & 6 & 18 & 18 & 25 & $<0.01$ \\
\hline Family history of diabetes, $\%$ & 24 & 27 & 28 & 23 & 0.2 \\
\hline $\begin{array}{l}\text { Use of postmenopausal } \\
\text { hormones, } \%\end{array}$ & & & & & $<0.01$ \\
\hline Premenopausal & 33 & 25 & 19 & 13 & \\
\hline Past use & 9 & 11 & 10 & 15 & \\
\hline Current use & 35 & 38 & 36 & 38 & \\
\hline Never used & 24 & 25 & 35 & 34 & \\
\hline Creatinine, mg/dL & $0.64(0.58-0.72)$ & $0.69(0.62-0.76)$ & $0.71(0.64-0.81)$ & $0.72(0.64-0.81)$ & $<0.01$ \\
\hline Estimated GFR, $\mathrm{mL} / \mathrm{min} / 1.73 \mathrm{~m}^{2}$ & $101.6(93.8-106.7)$ & $95.6(87.9-101.8)$ & $94.6(83.1-101.1)$ & $92.5(81.8-99.1)$ & $<0.01$ \\
\hline C-reactive protein, mg/dL & $0.14(0.06-0.36)$ & $0.15(0.06-0.35)$ & $0.17(0.07-0.32)$ & $0.15(0.09-0.32)$ & 0.8 \\
\hline Hemoglobin $\mathrm{A}_{1 c^{\prime}} \%$ & $5.5(5.4-5.8)$ & $5.6(5.4-5.7)$ & $5.6(5.5-5.8)$ & $5.6(5.5-5.8)$ & 0.2 \\
\hline Insulin, $\mu \mathrm{U} / \mathrm{mL}$ & $8.1(4.9-12.0)$ & $8.6(4.4-12.8)$ & $9.7(6.5-12.8)$ & $9.3(5.0-13.2)$ & 0.5 \\
\hline Plasma bicarbonate, $\mathrm{mmol} / \mathrm{L}$ & $19.5(18.3-19.9)$ & $21.4(20.9-21.7)$ & $23.1(22.7-23.6)$ & $25.3(24.4-26.4)$ & $<0.01$ \\
\hline \multicolumn{6}{|c|}{$\begin{array}{l}\text { Note: } \mathrm{COPD}=\text { chronic obstructive pulmonary disease, GFR = glomerular filtration rate, IQR = interquartile range, METs = metabolic equivalents, SD = standard } \\
\text { deviation. } \\
\text { *Unless otherwise stated. } \\
\text { †Percentages have been adjusted for age. } \\
\neq p \text { values are from analysis of variance for characteristics reported as means, Kruskal-Wallis test for those reported as medians, and } \chi^{2} \text { test for those reported as } \\
\text { percentages. } \\
\text { \$Physical activity reported on questionnaires was converted into METs using an established coding system. }{ }^{15} \\
\text { qDiabetes scores ranged from } 4 \text { to } 20, \text { with higher scores associated with a reduced risk of type } 2 \text { diabetes mellitus. }\end{array}$} \\
\hline
\end{tabular}


the association between low plasma bicarbonate and the risk of diabetes. We explored this in the subset of women (618 cases and 471 controls; one case was missing BMI data) who had measurement of C-reactive protein. We used models further adjusted for C-reactive protein. The ORs for diabetes by quartile of plasma bicarbonate were not materially different when we included C-reactive protein in the model.

\section{Interpretation}

Among adult women, a higher level of plasma bicarbonate was associated with lower odds of type 2 diabetes mellitus after controlling for potential confounders, including dietary, lifestyle and medical factors. The quartile analysis suggests a possible threshold effect, with the third and fourth quartiles having similar lower odds of diabetes, which was consistent with the findings of our median analysis.

Although we did not address mechanism in our study, the association between lower plasma bicarbonate and development of diabetes may be explained by metabolic acidosis promoting insulin resistance, and this association may be independent of systemic inflammation, given the similar results observed even after we adjusted for C-reactive protein. Furthermore, because the predominant determinants of net acid intake are acid precursors found in animal protein and base precursors found in potassium-rich fruits and vegetables, ${ }^{25}$ the finding that adjustment for intake of animal protein and potassium did not attenuate the association in our study suggests the explanation may be independent of dietary acid load.

Whether alkali supplementation reduces the risk of diabetes is not clear. Bicarbonate supplementation has been shown to increase insulin sensitivity among patients with kidney disease. ${ }^{26}$ Further, Maurer and colleagues ${ }^{6}$ showed that alkali supplementation decreased both serum cortisol levels and urinary cortisol excretion in a controlled metabolic study involving 9 people over 7 days. However, in a secondary analysis of a trial assessing bone outcomes in 153 people without diabetes aged 50 years and older who were administered alkali supplementation over 3 months, those who received bicarbonate supplementation did not have any change in fasting glucose, serum insulin level or insulin resistance as measured by the homeostasis model assessment for insulin resistance (HOMA-IR), nor was there any change in serum cortisol levels. ${ }^{27}$ These conflicting data necessitate further exploration of the effect of alkali supplementation on insulin resistance, cortisol excretion and the risk of diabetes over the long-term.

\section{Limitations}

Our study has several limitations. First, the range of mean plasma bicarbonate among our participants was lower than that commonly encountered clinically, which likely reflects systematic measurement error related to storage or other laboratory techniques. Because the samples were handled identically and the vials of case-control pairs and triplets were contiguous, we expect that such error would apply equally to both cases and controls. Therefore, although the exact values of plasma bicarbonate may not lend themselves to direct clinical interpretation and application, the observed trends remain valid.

Second, we did not have data on arterial or venous $\mathrm{pH}$ or renal net acid excretion for the participants in our study, which limits our ability to precisely characterize their acid-base status.

Third, because type 2 diabetes mellitus may

\begin{tabular}{|c|c|c|c|c|c|}
\hline \multirow[b]{2}{*}{$\begin{array}{l}\text { Group or } \\
\text { model }\end{array}$} & \multicolumn{4}{|c|}{ Quartile (plasma bicarbonate level, mmol/L); OR $(95 \% \mathrm{CI})$ * } & \multirow[b]{2}{*}{$\begin{array}{l}p \text { for linear } \\
\text { trend }\end{array}$} \\
\hline & $\begin{array}{l}\text { Quartile } 1 \\
(<20.6)\end{array}$ & $\begin{array}{c}\text { Quartile 2 } \\
(20.6-22.3)\end{array}$ & $\begin{array}{l}\text { Quartile } 3 \\
(22.4-23.9)\end{array}$ & $\begin{array}{l}\text { Quartile } 4 \\
(>23.9)\end{array}$ & \\
\hline Cases, no. & 188 & 165 & 139 & 138 & \\
\hline Controls, no. & 189 & 176 & 183 & 182 & \\
\hline \multicolumn{6}{|l|}{ Model } \\
\hline $1+$ & Referent & $0.93(0.69-1.25)$ & $0.75(0.55-1.01)$ & $0.74(0.55-1.01)$ & 0.03 \\
\hline $2 \ddagger$ & Referent & $0.92(0.67-1.25)$ & $0.70(0.51-0.97)$ & $0.75(0.54-1.05)$ & 0.04 \\
\hline \multicolumn{6}{|c|}{$\begin{array}{l}\text { Note: } \mathrm{Cl}=\text { confidence interval, } \mathrm{OR}=\text { odds ratio. } \\
\text { *Unless otherwise stated. } \\
\text { †Adjusted for matching factors: age at blood draw (continuous), ethnic background (white v. non-white) and fasting status at } \\
\text { blood draw (binary). } n=630 \text { cases and } 730 \text { controls. } \\
\text { fAdjusted for matching factors, body mass index (continuous), history of hypertension (binary) and plasma creatinine } \\
(<0.6 \mathrm{mg} / \mathrm{dL}, 0.6-0.8 \mathrm{mg} / \mathrm{dL},>0.8 \mathrm{mg} / \mathrm{dL}) . n=629 \text { cases and } 729 \text { controls. One case and one control in this model were missing } \\
\text { data for body mass index. }\end{array}$} \\
\hline
\end{tabular}


follow an indolent course before diagnosis, subclinical disease may be present before formal diagnosis. However, the ORs did not change markedly after we excluded people who received a diagnosis of diabetes in the first four years of follow-up or people with hemoglobin $\mathrm{A}_{1 \mathrm{c}}$ greater than $6.5 \%$ at baseline.

Fourth, we had only one measurement of plasma bicarbonate, so we cannot draw conclusions as to how changes in bicarbonate over time affect the risk of diabetes. However, previous studies have reported a within-person coefficient of variation of $4.2 \%$ for repeated bicarbonate measurements, ${ }^{28}$ suggesting that within-person variation in plasma bicarbonate levels over time is low.

Fifth, although we included extensive data on potential confounders, confounding by other unmeasured or unknown factors may still exist.

Finally, our results may not be generalizable to men or to racial or ethnic minority groups.

\section{Conclusion}

Our study showed an association between higher plasma bicarbonate levels and reduced risk of incident type 2 diabetes mellitus among women in the Nurses' Health Study. Further research is required to confirm this finding in other populations, to elucidate the mechanism by which this occurs, and to explore increased dietary or supplemental alkali intake as a novel strategy for prevention of type 2 diabetes mellitus.

\section{References}

1. Stumvoll M, Goldstein BJ, van Haeften TW. Type 2 diabetes: principles of pathogenesis and therapy. Lancet 2005;365:1333-46.

2. Shulman GI. Unraveling the cellular mechanism of insulin resistance in humans: new insights from magnetic resonance spectroscopy. Physiology (Bethesda) 2004;19:183-90.

3. DeFronzo RA, Beckles AD. Glucose intolerance following chronic metabolic acidosis in man. Am J Physiol 1979;236:E328-34.

4. Igarashi M, Yamatani K, Fukase N, et al. Effect of acidosis on insulin binding and glucose uptake in isolated rat adipocytes. Tohoku J Exp Med 1993;169:205-13.

5. Whittaker J, Cuthbert C, Hammond VA, et al. The effects of metabolic acidosis in vivo on insulin binding to isolated rat adipocytes. Metabolism 1982;31:553-7.

6. Maurer M, Riesen W, Muser J, et al. Neutralization of Western diet inhibits bone resorption independently of $\mathrm{K}$ intake and reduces cortisol secretion in humans. Am J Physiol Renal Physiol 2003;284:F32-40.

7. Andrews RC, Walker BR. Glucocorticoids and insulin resistance: old hormones, new targets. Clin Sci (Lond) 1999;96:513-23.

8. Farwell WR, Taylor EN. Serum bicarbonate, anion gap and insulin resistance in the National Health and Nutrition Examination Survey. Diabet Med 2008;25:798-804.

9. Crawford SO, Hoogeveen RC, Brancati FL, et al. Association of blood lactate with type 2 diabetes: the Atherosclerosis Risk in Communities Carotid MRI Study. Int J Epidemiol 2010;39:1647-55.

10. Ohlson LO, Larsson B, Bjorntorp P, et al. Risk factors for type 2 (non-insulin-dependent) diabetes mellitus. Thirteen and one-half years of follow-up of the participants in a study of Swedish men born in 1913. Diabetologia 1988;31:798-805.
11. Avogaro A, Crepaldi C, Miola M, et al. High blood ketone body concentration in type 2 non-insulin dependent diabetic patients. J Endocrinol Invest 1996;19:99-105.

12. Cupisti A, Meola M, D'Alessandro C, et al. Insulin resistance and low urinary citrate excretion in calcium stone formers. Biomed Pharmacother 2007;61:86-90.

13. Maalouf NM, Cameron MA, Moe OW, et al. Low urine $\mathrm{pH}$ : a novel feature of the metabolic syndrome. Clin J Am Soc Nephrol 2007;2:883-8.

14. Manson JE, Rimm EB, Stampfer MJ, et al. Physical activity and incidence of non-insulin-dependent diabetes mellitus in women. Lancet 1991;338:774-8.

15. Ainsworth BE, Haskell WL, Leon AS, et al. Compendium of physical activities: classification of energy costs of human physical activities. Med Sci Sports Exerc 1993;25:71-80.

16. Hu FB, Manson JE, Stampfer MJ, et al. Diet, lifestyle, and the risk of type 2 diabetes mellitus in women. $N$ Engl J Med 2001; 345:790-7.

17. Willett W. Nutritional epidemiology. 2nd ed. New York (NY): Oxford University Press; 1998

18. Willett WC, Sampson L, Stampfer MJ, et al. Reproducibility and validity of a semiquantitative food frequency questionnaire. Am J Epidemiol 1985;122:51-65.

19. Rimm EB, Stampfer MJ, Colditz GA, et al. Validity of self-reported waist and hip circumferences in men and women. Epidemiology 1990;1:466-73.

20. Hu FB, Sigal RJ, Rich-Edwards JW, et al. Walking compared with vigorous physical activity and risk of type 2 diabetes in women: a prospective study. JAMA 1999;282:1433-9.

21. Levey AS, Stevens LA, Schmid CH, et al. A new equation to estimate glomerular filtration rate. Ann Intern Med 2009;150:604-12.

22. American Diabetes Association. Diagnosis and classification of diabetes mellitus. Diabetes Care 2010;33(Suppl 1):S62-9.

23. Farwell WR, Taylor EN. Serum anion gap, bicarbonate and biomarkers of inflammation in healthy individuals in a national survey. CMAJ 2010;182:137-41.

24. Hu FB, Meigs JB, Li TY, et al. Inflammatory markers and risk of developing type 2 diabetes in women. Diabetes 2004;53:693-700.

25. Alpern RJ, Hebert SC, editors. Seldin and Giebisch's the kidney: physiology \& pathophysiology. 4th ed. Burlington (MA): Elsevier Academic Press; 2008.

26. Reaich D, Graham KA, Channon SM, et al. Insulin-mediated changes in PD and glucose uptake after correction of acidosis in humans with CRF. Am J Physiol 1995;268:E121-6.

27. Harris SS, Dawson-Hughes B. No effect of bicarbonate treatment on insulin sensitivity and glucose control in non-diabetic older adults. Endocrine 2010;38:221-6.

28. Harris EK, Kanofsky P, Shakarji G, et al. Biological and analytic components of variation in long-term studies of serum constituents in normal subjects. II. Estimating biological components of variation. Clin Chem 1970;16:1022-7.

Affiliations: From the Renal Division (Mandel, Curhan) and the Channing Division of Network Medicine (Mandel, Curhan, Hu, Taylor), Department of Medicine, Brigham and Women's Hospital and Harvard Medical School; the Departments of Epidemiology (Mandel, Curhan, Hu) and Nutrition (Hu), Harvard School of Public Health, Boston, Mass.; and the Division of Nephrology and Transplantation (Taylor), Maine Medical Center, Portland, Me.

Contributors: Ernest Mandel, Gary Curhan and Eric Taylor contributed to the conception and design of the study, data acquisition, analysis and interpretation. Frank Hu contributed to the data acquisition, analysis and interpretation. Ernest Mandel performed the literature review and drafted the manuscript. All of the authors performed a critical review of the manuscript and approved the final version of the manuscript submitted for publication.

Funding: Support for this study was provided by the American Kidney Fund Clinical Scientist in Nephrology Program and National Institutes of Health (NIH) Grants CA49449, CA87969, DK007527, DK84019 and DK91417. 